\section{BRAZIULIAN JOURNAL}

OF MEDICAL AND BIOLOGICAL RESFARCH

www.bjournal.com.br
ISSN 0100-879X

Volume 44 (7) 606-728 July 2011

BIOMEDICAL SCIENCES

AND

CLINICAL INVESTIGATION

Braz J Med Biol Res, July 2011, Volume 44(7) 660-665

doi: 10.1590/S0100-879X2011007500058

Characterization and analysis of the outcome of adults with acute myeloid leukemia treated in a Brazilian University hospital over three decades

J.T. Souto Filho, R.D. Portugal, M. Loureiro, W. Pulcheri and M. Nucci

The Brazilian Journal of Medical and Biological Research is partially financed by
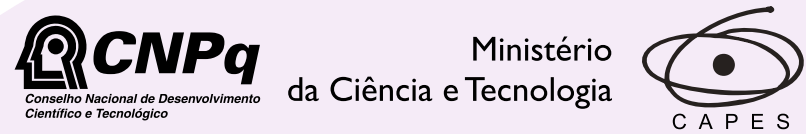

Ministério da Educação
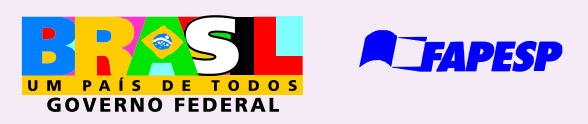

Institutional Sponsors
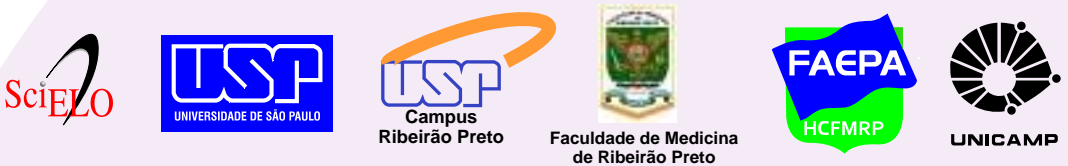

Hotsite of proteomics metabolomics developped by:

GE Healthcare 


\title{
Characterization and analysis of the outcome of adults with acute myeloid leukemia treated in a Brazilian University hospital over three decades
}

\author{
J.T. Souto Filho, R.D. Portugal, M. Loureiro, W. Pulcheri and M. Nucci \\ Hospital Universitário Clementino Fraga Filho, Universidade Federal do Rio de Janeiro, Rio de Janeiro, RJ, Brasil
}

\begin{abstract}
We evaluated the outcome of 227 patients with acute myeloid leukemia during three decades (period 1 - 1980's, N = 89; period 2 - 1990's, N = 73; period 3 - 2000's, N = 65) at a single institution. Major differences between the three groups included a higher median age, rates of multilineage dysplasia and co-morbidities, and a lower rate of clinical manifestations of advanced leukemia in recent years. The proportion of patients who received induction remission chemotherapy was 66,75 , and $85 \%$ for periods 1 , 2 , and 3 , respectively $(P=0.04)$. The median survival was 40,77 , and 112 days, and the 5 -year overall survival was 7,13 , and $22 \%$, respectively $(P=0.01)$. The median disease-free survival was 266,278 , and 386 days $(P=0.049)$. Survival expectation for patients with acute myeloid leukemia has substantially improved during this 30 -year period, due to a combination of lower tumor burden and a more efficient use of chemotherapy and supportive care.
\end{abstract}

Key words: Acute myeloid leukemia; Survival; Prognosis

\section{Introduction}

Over the past three decades, the outcome of patients with acute myeloid leukemia $(\mathrm{AML})$ has improved with the incorporation of intensive induction and post-remission treatment, including allogeneic and autologous hematopoietic stem cell transplantation (HCT), and improvements in supportive care (1-3). However, while randomized clinical trials have reported high long-term survival rates, the results of population-based studies have shown long-term remissions in a quarter of patients only (4-7). Furthermore, retrospective studies performed in developing countries have reported even lower overall survival rates (8-13).

Fifteen years ago, our group reported the treatment and outcome of AML at our institution, and discussed several reasons for the low remission and survival rates observed, including poor hospital convenience, health system deficiency, patients' poor socioeconomic background, and different biological aspects of AML. A remarkable finding was that $\sim 40 \%$ of patients did not receive any chemotherapy because of very poor general conditions, and this was the main reason for the poor results achieved (14).

In order to confirm recent improvements in treatment outcomes, we retrospectively reviewed the clinical characteristics, treatment and outcome of all patients with a diagnosis of AML admitted to Hospital Universitário Clementino Fraga Filho, Universidade Federal do Rio de Janeiro, over the past 30 years.

\section{Material and Methods}

This retrospective cohort study included all patients diagnosed with AML at Hospital Universitário Clementino Fraga Filho, Universidade Federal do Rio de Janeiro, Brazil, from January 1979 to December 2008. Patients were identified from hospital medical records and the Hematology Service registry. Patients with acute promyelocytic leukemia (APL) and those previously treated at other institutions were excluded. The study was approved by the Hospital Universitário Clementino Fraga Filho Ethics Committee.

The diagnosis of AML was based on procedures available at the time, including bone marrow aspiration and biopsy, and cytogenetic and immunophenotype analyses. Cases were classified according to French-American-British 
(FAB) criteria (15). For the purpose of this study we reviewed the slides for FAB classification and for the detection of the presence of multilineage dysplasia. The treatment approach varied between time periods; for the purpose of the present analysis, treatment was classified as curativeintent (when standard induction was given), palliative-intent (other regimens), and no chemotherapy. Standard remission induction was based on treatment with cytarabine plus an anthracycline in most patients. Until 1985, the regimen consisted of $100 \mathrm{mg} / \mathrm{m}^{2}$ thioguanine administered orally every $12 \mathrm{~h}$ on days 1 to $7,100 \mathrm{mg} \cdot\left(\mathrm{m}^{2}\right)^{-1} \cdot$ day $^{-1}$ cytarabine administered by continuous intravenous infusion on days 1 to 7 , and $30 \mathrm{mg} / \mathrm{m}^{2}$ doxorubicin on days 1 to 3 (TAD). After 1985 , induction was changed to $200 \mathrm{mg} \cdot\left(\mathrm{m}^{2}\right)^{-1} \cdot 7$ days $^{-1}$ cytarabine plus an anthracycline for 3 days, either $45 \mathrm{mg} /$ $\mathrm{m}^{2}$ daunorubicin or $30 \mathrm{mg} / \mathrm{m}^{2}$ doxorubicin $(7+3)$. Patients with residual leukemia at day 14 received a similar but shorter second induction course [cytarabine for 5 days + anthracycline for 2 days (5+2)]. Post-remission treatment evolved from 12 maintenance cycles in the early TAD period to 4 courses of infusional cytarabine $\left(400 \mathrm{mg} / \mathrm{m}^{2}\right.$ plus $30 \mathrm{mg} / \mathrm{m}^{2}$ doxorubicin on days 1 to 3 ) until 1992, then to 2-4 courses of high-dose cytarabine $\left(1 \mathrm{~g} / \mathrm{m}^{2}\right.$ every $12 \mathrm{~h}$ on days 1 to 4 and $30 \mathrm{mg} / \mathrm{m}^{2}$ doxorubicin on days 1 to 3 ), and finally, after 1999, to 2-4 cycles of high-dose cytarabine (3 $\mathrm{g} / \mathrm{m}^{2}$ every $12 \mathrm{~h}$ on days 1,3 , and 5 ).

Complete remission (CR), treatment failure and relapse were defined according to the International Working Group for AML (16) and the recommendations from an international expert panel (17). Briefly, CR required $<5 \%$ blasts to be present in a bone marrow aspirate sample, with an absolute neutrophil count $>1000 / \mu \mathrm{L}$ and a platelet count $>100,000 / \mu \mathrm{L}$.

Overall survival (OS) was calculated from the diagnosis of AML until the date of death or last follow-up. Disease-free survival (DFS) applies only to patients who obtained CR, and was calculated from the time of CR assessment to the date of relapse, last follow-up or death.

We divided the 30-year period into three parts: 1980's (period 1), 1990's (period 2), and 2000's (period 3). The following parameters were compared between the three periods: age, gender, FAB subgroup, multilineage dysplasia, presence of co-morbidities (diabetes, cardiac, lung, liver, and renal disease), clinical manifestations at presentation (fever, gingival hyperplasia, lymphadenopathy, hepatomegaly, splenomegaly, bleeding, disseminated intravascular coagulation, and lung, skin or central nervous system infiltration by leukemia), infection before treatment (classified as oral/ oropharyngeal, gastrointestinal, cutaneous, pulmonary, sinusal, urinary, bloodstream, or fever of unknown origin), and baseline laboratory tests (leukocyte and platelet count, serum hemoglobin and lactate dehydrogenase).

Dichotomous variables were compared by the Fisher exact test or the chi-square test, and continuous variables were compared by the Kruskal-Wallis test. Actuarial curves of OS and DFS were constructed using the Kaplan-Meier method, and compared by the log-rank test. Predictors of outcome (OS) were assessed by Cox regression analysis, and the results are reported as hazard ratio $(\mathrm{HR})$ with the corresponding $95 \%$ confidence interval $(95 \% \mathrm{Cl})$. Variables with $P$ value $<0.1$ by univariate analysis were entered in multivariate analysis. $P$ values were two-sided, and were considered to be statistically significant with values $<0.05$. All statistical analyses were performed using the SPSS 11.0 software (SPSS Inc., USA, 1989-2001).

\section{Results}

Of 295 patients with AML identified in hospital records, 68 were excluded for the following reasons: 52 with APL, 11 with biphenotypic leukemia, and 3 previously treated at other institutions. Among the remaining 227 patients, 125 were males. The median age was 45 years (range 12-91), and $25 \%$ were $>60$ years old. The most common FAB subtypes were M4 and M2 (27 and 22.5\%, respectively). AML with multilineage dysplasia was present in $18.5 \%$ of patients.

Fifty-eight patients $(25.5 \%)$ did not receive treatment. Among the 169 patients receiving remission induction chemotherapy, $75 \%$ were treated with cytarabine in continuous infusion for 7 days plus an anthracycline for 3 days (7+3 regimen), $15 \%$ received TAD and $10 \%$ received other regimens. Fifteen patients died before day 14 of remission induction and were not assessed for response to chemotherapy. Among the remaining 154, CR was achieved in 88 (57.1\% of patients receiving remission induction), after a single course of induction in 72, and after a second course in 16 (5+2 regimen). The median time (days) to achieve $>1000$ neutrophils $/ \mu \mathrm{L}$ and $>100,000$ platelets $/ \mu \mathrm{L}$ was 27 (range 4-153) and 28 (range 9-104) days, respectively.

Among the 88 patients who obtained $\mathrm{CR}, 5$ received an autologous $\mathrm{HCT}, 10$ received allogeneic $\mathrm{HCT}$ and 70 received post-induction chemotherapy ( 1 cycle in 15 patients, 2 cycles in 37,3 cycles in 6 , and $\geq 4$ cycles in 12 ).

The median survival of the 227 patients was 55 days (range 28-82). Among treated patients, the median survival was 147 days (range 54-239). The 3- and 5-year OS was 14 and $13 \%$, respectively, for all patients, and 18 and $17 \%$, respectively, for treated patients. The majority of deaths occurred among non-responders and relapsed patients (60\%), followed by deaths during the induction phase (30\%), and among patients in CR (10\%). Stratified according to these three groups, infection was the leading cause of death (51, 72 and $77 \%)$. Other causes were bleeding $(9,15$, and $0 \%)$ and treatment-related toxicity $(0,3$, and $7 \%)$.

\section{Comparative analysis of three decades}

The number of cases for each time period and their characteristics are detailed in Table 1. Major differences in baseline characteristics included a higher proportion of multilineage dysplasia and higher median age over time 
(and, as a consequence, a higher rate of co-morbidities in recent years). By contrast, in recent years the rate of clinical manifestations of advanced leukemia, such as hepatosplenomegaly, bleeding, fever, documented infection, and baseline leukocyte count was lower.

The proportion of patients receiving treatment increased over time $(66,75$, and $85 \%$ during periods 1,2 , and 3$)$. Likewise, the proportion of patients undergoing $\mathrm{HCT}$ increased (zero, 7 , and $20 \%$ of patients receiving treatment during periods 1, 2, and 3). The median survival during periods 1 ,
2 , and 3 was 40,77 , and 112 days, respectively, and the 5 -year OS was 7,13 , and $22 \%$, respectively $(P=0.01$; Figure $1 \mathrm{~A})$. Among treated patients $(\mathrm{N}=169)$ the median survival was 68, 205, and 208 days, respectively, and the 5-year OS was 10,17 , and $26 \%$, respectively $(P=0.05$; Figure 1B). The median DFS for all patients in CR $(\mathrm{N}=88)$ was 308 days (range $244-371$ ), and the 5-year DFS was $29 \%$. The median DFS per period was 266 days during period 1 , 278 during period 2 , and 386 days during period 3 , and the 5 -year DFS was 13,21 , and $44 \%$, respectively $(P=0.049$;

Table 1. Characteristics of 227 patients with acute myeloid leukemia stratified by decade of diagnosis.

\begin{tabular}{|c|c|c|c|}
\hline & $\begin{array}{c}\text { Period } 1 \\
\text { (1980's; N = 89) }\end{array}$ & $\begin{array}{c}\text { Period } 2 \\
\text { (1990's; } \mathrm{N}=73 \text { ) }\end{array}$ & $\begin{array}{c}\text { Period } 3 \\
\text { (2000's; N = 65) }\end{array}$ \\
\hline Gender (male:female) & 40:25 & $34: 39$ & $51: 38$ \\
\hline Age in years, median (range) ${ }^{*}$ & $37(12-90)$ & $42(13-91)$ & $53(15-89)$ \\
\hline Age $>60$ years, $\mathrm{N}(\%)^{*}$ & $17(19)$ & $17(23)$ & $22(34)$ \\
\hline \multicolumn{4}{|l|}{ FAB classification, $N(\%)$} \\
\hline M2 & $21(24)$ & $14(19)$ & $16(25)$ \\
\hline M4 & $29(33)$ & $17(23)$ & $16(25)$ \\
\hline Other & $39(44)$ & $42(58)$ & $33(50)$ \\
\hline Multi-lineage dysplasia, $\mathrm{N}(\%)^{*}$ & $6(7)$ & $16(22)$ & $20(31)$ \\
\hline Presence of co-morbidities, $\mathrm{N}(\%)^{\# *}$ & $17(19)$ & $18(25)$ & $25(38.5)$ \\
\hline \multicolumn{4}{|l|}{ Clinical manifestations at presentation, $\mathrm{N}(\%)$} \\
\hline Gingival hyperplasia* & $20(22.5)$ & $15(20.5)$ & $4(6)$ \\
\hline Lymphadenopathy* & $52(58)$ & $22(30)$ & $14(21.5)$ \\
\hline Hepatomegaly* & $55(62)$ & $26(36)$ & $10(15)$ \\
\hline Splenomegaly* & $38(43)$ & $18(25)$ & $4(6)$ \\
\hline Fever* & $66(74)$ & $52(71)$ & $30(46)$ \\
\hline Bleeding* & $51(57)$ & $33(45)$ & $22(34)$ \\
\hline Infection, $\mathrm{N}(\%)^{*}$ & $63(71)$ & $50(68.5)$ & $31(48)$ \\
\hline Oropharyngeal* & $13(15)$ & $4(5.5)$ & $2(3)$ \\
\hline Gastrointestinal & $5(6)$ & $0(0)$ & $4(6)$ \\
\hline Fever of unknown origin & $15(17)$ & $18(25)$ & $9(14)$ \\
\hline Blood & $1(1)$ & $1(1)$ & $1(1.5)$ \\
\hline Skin & $14(16)$ & $12(16)$ & $6(9)$ \\
\hline Lung & $15(17)$ & $11(15)$ & $4(6)$ \\
\hline Sinusitis & $1(1)$ & $0(0)$ & $1(1.5)$ \\
\hline Mouth & $8(9)$ & $11(15)$ & $4(6)$ \\
\hline Urine & $3(3)$ & $3(4)$ & $1(1.5)$ \\
\hline Baseline leukocyte count $\left(\times 10^{3} / \mu \mathrm{L}\right)$, median $(\text { range })^{*}$ & $27.6(1.5-800)$ & $14.1(0.4-509)$ & $8.3(0.6-212)$ \\
\hline Baseline hemoglobin ( $\mathrm{g} / \mathrm{dL})$, median (range) & $7.2(2.2-15.1)$ & $7.8(1.9-13.8)$ & $7.5(3.2-12.9)$ \\
\hline Baseline platelet count $\left(\times 10^{3} / \mu \mathrm{L}\right)$, median (range) & $36(1-999)$ & $35(5-290)$ & $34(1-303)$ \\
\hline Received chemotherapy, N (\%)* & $59(66)$ & $55(75)$ & $55(85)$ \\
\hline Obtained complete remission, $\mathrm{N}(\%)$ & $25 / 59(42.4)$ & $33 / 55(60)$ & $30 / 55(54.5)$ \\
\hline Received $\mathrm{HCT}^{+*}$ & $0 / 59$ & $4 / 55(7)$ & $11 / 55(20)$ \\
\hline
\end{tabular}

Data are reported as median (range) or number (\%). FAB classification = French-American-British classification; $\mathrm{HCT}=$ hematopoietic cell transplantation. ${ }^{*} \mathrm{P}<0.05$ for the comparison of periods 1,2 , and 3 (chi-square test, Fisher exact test, and Kruskal-Wallis test). \#Co-morbidities included diabetes and cardiac, lung, liver, and renal diseases. ${ }^{+} 2$ autologous and 2 allogeneic in the 1990's and 3 autologous and 8 allogeneic in the 2000's. 

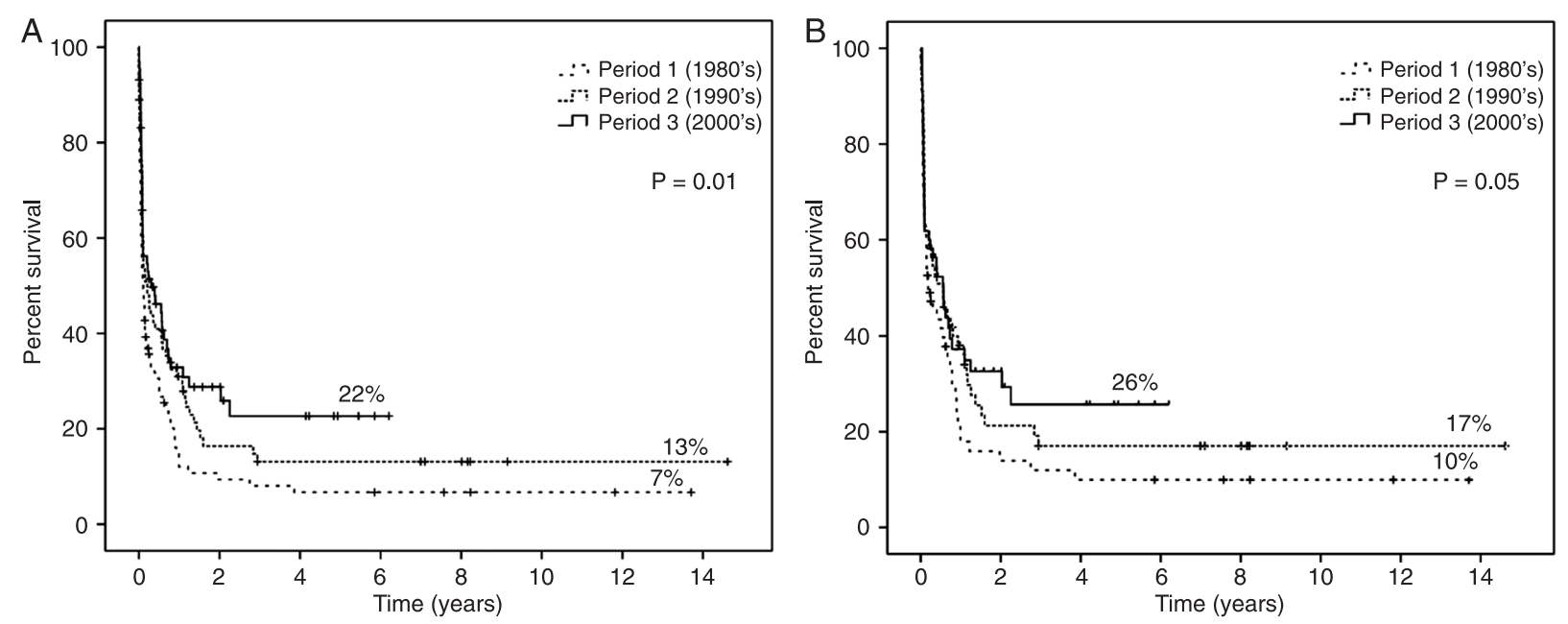

Figure 1. Overall survival as a function of decade of diagnosis. A, All patients; $B$, treated patients.

Figure 2). Since there was a significant difference in the proportion of patients undergoing HCT during the 3 periods, we re-ran the analysis excluding those patients. There were no significant difference in OS $(P=0.224)$ and DFS $(P=$ 0.512 ) when the three periods were compared.

\section{Prognostic factors}

As shown in Table 2, variables significantly associated with poor outcome (overall survival) by multivariate analysis were age $>60$ years $(\mathrm{HR}=1.76,95 \% \mathrm{Cl}=1.25-2.49)$, decade of treatment $(\mathrm{HR}=1.24,95 \% \mathrm{Cl}=1.01-1.52)$, concomitant kidney disease $(\mathrm{HR}=2.84,95 \% \mathrm{Cl}=1.05-7.89)$, baseline hepatomegaly $(\mathrm{HR}=1.48,95 \% \mathrm{Cl}=1.08-2.04)$, bleeding $(\mathrm{HR}=1.48,95 \% \mathrm{Cl}=1.10-2.00)$, infection in the gastrointestinal tract $(\mathrm{HR}=2.32,95 \% \mathrm{Cl}=1.14-4.69)$, and $\mathrm{FAB}$ subtype other than $\mathrm{M} 2(\mathrm{HR}=1.69,95 \% \mathrm{Cl}=1.16-5 \cdot 27)$.

\section{Discussion}

Our study shows that some characteristics of adult patients with AML have changed over the past 3 decades, with a higher proportion of older patients, with co-morbidities and multilineage dysplasia. The higher proportion of elderly patients is expected as a consequence of the increasing longevity of the population (18). Indeed, in Rio de Janeiro, during the same period there was an increase of people more than 60 years old, from $8.7 \%$ in the 1980 's to $11.2 \%$ in the 1990 's, and $12.8 \%$ in the 2000's (19). Furthermore, AML in the elderly is associated with several biological and clinical features, including a high frequency of co-morbidities and multilineage dysplasia, as observed in our cohort (20).

In addition, despite the higher incidence of these characteristics, the outcome improved over time. This could be a reflection of a lower disease burden, as observed by the lower frequency of lymphadenopathy, hepatomegaly,

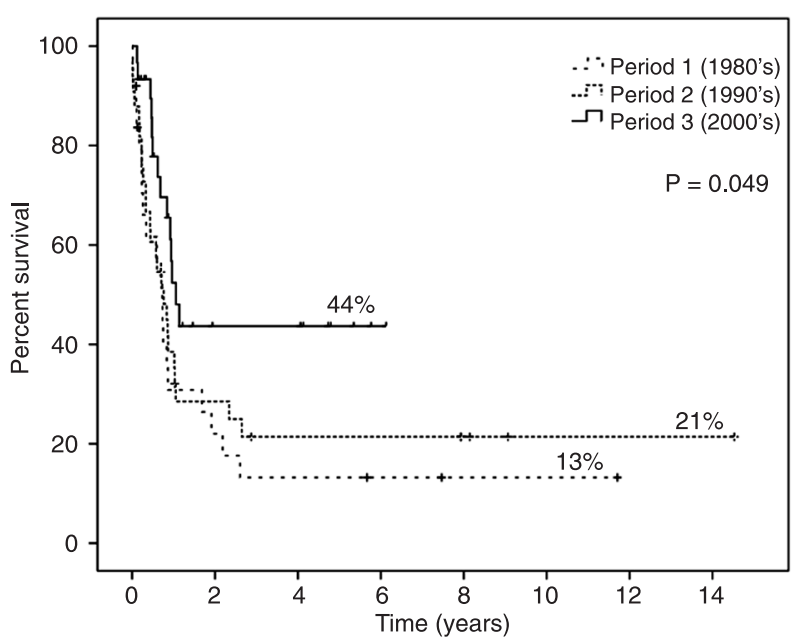

Figure 2. Disease-free survival as a function of decade of diagnosis.

splenomegaly, fever, bleeding, and infection at diagnosis, as well as the median leukocyte count at baseline. In a previous report from our group, $37 \%$ of patients with AML were too sick at diagnosis to receive any treatment (14). In the present study, we observed that the proportion of patients receiving treatment increased $\sim 10 \%$ per decade: $66 \%$ in the 1980 's, $75 \%$ in the 1990 's, and $85 \%$ in the 2000 's. Taken together, the increased proportion of patients being treated and the lower tumor burden on admission suggest that the primary health care system of Brazil has generally improved.

Moreover, the 5-year overall survival may have improved not simply as a consequence of a higher proportion of patients receiving chemotherapy, since there was a trend for an increased OS among treated patients (from 10\% in the 
Table 2. Univariate and multivariate analysis of factors associated with poor outcome (overall survival).

\begin{tabular}{|c|c|c|c|c|c|c|}
\hline \multirow[t]{2}{*}{ Variable $^{\mathrm{a}}$} & \multicolumn{3}{|c|}{ Univariate } & \multicolumn{3}{|c|}{ Multivariate } \\
\hline & $\mathrm{HR}$ & $95 \% \mathrm{Cl}$ & $\mathrm{P}$ & HR & $95 \% \mathrm{Cl}$ & $P$ \\
\hline Age $>60$ years & 1.68 & $1.20-2.36$ & 0.002 & 1.76 & $1.25-2.49$ & 0.001 \\
\hline Decade & 1.32 & $1.10-1.58$ & 0.003 & 1.24 & $1.01-1.52$ & 0.04 \\
\hline Heart disease & 1.53 & $1.08-2.17$ & 0.02 & & & NS \\
\hline Lung disease & 1.92 & $0.94-3.95$ & 0.08 & & & NS \\
\hline Kidney disease & 2.65 & $0.98-7.18$ & 0.06 & 2.87 & $1.05-7.89$ & 0.04 \\
\hline Any co-morbidity & 1.60 & $1.15-2.21$ & 0.005 & & & NS \\
\hline Hepatomegaly & 1.79 & $1.34-2.40$ & 0.001 & 1.48 & $1.08-2.04$ & 0.02 \\
\hline Splenomegaly & 1.36 & $0.99-1.88$ & 0.06 & & & NS \\
\hline Bleeding & 1.59 & $1.19-2.12$ & 0.002 & 1.48 & $1.10-2.00$ & 0.01 \\
\hline Infection in the gastrointestinal tract & 2.84 & $1.44-5.61$ & 0.003 & 2.32 & $1.14-4.69$ & 0.02 \\
\hline Lung infection & 1.49 & $0.99-2.23$ & 0.05 & & & NS \\
\hline FAB sub-group other than M2 & 1.92 & $1.23-2.94$ & 0.004 & 1.69 & $1.16-5.27$ & 0.007 \\
\hline
\end{tabular}

$\mathrm{HR}=$ hazard ratio $; 95 \% \mathrm{Cl}=95 \%$ confidence interval; $\mathrm{FAB}=$ French-American-British classification; $N S=$ not significant. aVariables with a $P$ value $\geq 0.1$ by univariate analysis were: gender, multilineage dysplasia, liver diseases, diabetes, gingival hyperplasia, lymphadenopathy, fever, oropharyngeal infection, fever of unknown origin, bloodstream infection, skin infections, sinusitis, baseline hemoglobin, and platelets.

1980 's to $26 \%$ in the 2000 's). The most significant improvement in the outcome can be appreciated in the 5-year DFS curve. In the 2000's, DFS was three times higher than that of the 1980's (44 vs 13\%). This is probably a result of better consolidation or intensification employed more recently, including $\mathrm{HCT}$, as well as progresses in supportive care, since there were no significant differences in the rates of complete remission (42.4\% in the 1980's, $60 \%$ in the 1990 's, and $54.5 \%$ in the 2000 's). Indeed, when we excluded patients undergoing $\mathrm{HCT}$, the differences in OS and DFS were much lower, and lacked statistical significance.

The multivariate analysis of prognostic factors showed that decade was significantly associated with the outcome. This, most probably, reflects a combination of elements related to diagnosis and treatment: effective induction treatment, higher proportion of treated patients, intensive postremission therapy, better management of chemotherapyinduced toxicity, appropriate use of antimicrobial agents, development of autologous and allogeneic transplantation, and progresses in overall supportive care $(4,9,18,21)$.

Among the other variables, age has proved to be an

\section{References}

1. Estey E, Dohner H. Acute myeloid leukaemia. Lancet 2006; 368: 1894-1907.

2. Milligan DW, Grimwade D, Cullis JO, Bond L, Swirsky D, Craddock $C$, et al. Guidelines on the management of acute myeloid leukaemia in adults. Br J Haematol 2006; 135: 450-474.

3. Tallman MS, Gilliland DG, Rowe JM. Drug therapy for acute important prognostic factor in many studies $(4,22-25)$. In addition, AML with multilineage dysplasia has been associated with a poor prognosis. In our analysis, this variable was not significant by multivariate analysis, probably due to a strong correlation between multilineage dysplasia and older age (26).

Other prognostic factors identified in our analysis have been reported in other studies as important predictors of outcome, including kidney disease $(23,27,28)$, hepatomegaly (29), and bleeding (30). The presence of the FAB M2 subgroup was protective, possibly as a consequence of the relationship between FAB M2 subgroup and well-defined prognostic factors such as $\mathrm{t}(8 ; 21)$ translocation (31), and a lower frequency of FLT3 mutations (32).

The present study suffers from the limitations of retrospective studies, especially the lack and inconsistency of data collected from patients' charts, without a prospectively collected case report form. In addition, the analysis of prognostic factors is hampered by the fact that cytogenetics, an important prognostic factor in $\mathrm{AML}(33,34)$, was performed in a minority of patients from this cohort.

myeloid leukemia. Blood 2005; 106: 1154-1163.

4. Derolf AR, Kristinsson SY, Andersson TM, Landgren O, Dickman PW, Bjorkholm M. Improved patient survival for acute myeloid leukemia: a population-based study of 9729 patients diagnosed in Sweden between 1973 and 2005. Blood 2009; 113: 3666-3672. 
5. Pulte D, Gondos A, Brenner H. Improvements in survival of adults diagnosed with acute myeloblastic leukemia in the early 21st century. Haematologica 2008; 93: 594-600.

6. Seo T, Fukushima T, Inoue H, Imamura S, Urasaki Y, Yoshida A, et al. Long-term follow-up of the clinical efficacy of chemotherapy for acute myeloid leukemia at a single institute. $J$ Infect Chemother 2001; 7: 156-162.

7. Xie Y, Davies SM, Xiang Y, Robison LL, Ross JA. Trends in leukemia incidence and survival in the United States (19731998). Cancer 2003; 97: 2229-2235.

8. Pagnano KB, Traina F, Takahashi T, Oliveira GB, Rossini MS, Lorand-Metze I, et al. Conventional chemotherapy for acute myeloid leukemia: a Brazilian experience. Sao Paulo Med J 2000; 118: 173-178.

9. Luke C, Nguyen AM, To B, Seshadri R, Hughes T, Bardy P, et al. Myeloid leukaemia treatment and survival - the South Australian experience, 1977 to 2002. Asian Pac J Cancer Prev 2006; 7: 227-233.

10. Rego MF, Pinheiro GS, Metze K, Lorand-Metze I. Acute leukemias in Piaui: comparison with features observed in other regions of Brazil. Braz J Med Biol Res 2003; 36: 331-337.

11. Fagundes EM, Rocha V, Gloria AB, Clementino NC, Quintao JS, Guimaraes JP, et al. De novo acute myeloid leukemia in adults younger than 60 years of age: socioeconomic aspects and treatment results in a Brazilian university center. Leuk Lymphoma 2006; 47: 1557-1564.

12. Capra M, Vilella L, Pereira WV, Coser VM, Fernandes MS, Schilling MA, et al. Estimated number of cases, regional distribution and survival of patients diagnosed with acute myeloid leukemia between 1996 and 2000 in Rio Grande do Sul, Brazil. Leuk Lymphoma 2007; 48: 2381-2386.

13. Bittencourt R, Fogliato L, Daudt L, Bittencourt HNS, Friederich JR, Fernandes F, et al. Leucemia mielóide aguda: perfil de duas décadas do Serviço de Hematologia do Hospital das Clínicas de Porto Alegre - RS. Rev Bras Hematol Hemoter 2003; 25: 17-24.

14. Pulcheri W, Spector N, Nucci M, de Morais JC, Pimenta G, de Oliveira HP. The treatment of acute myeloid leukemia in Brazil: progress and obstacles. Haematologica 1995; 80: 130-135.

15. Bennett JM, Catovsky D, Daniel MT, Flandrin G, Galton DA, Gralnick HR, et al. Proposed revised criteria for the classification of acute myeloid leukemia. A report of the FrenchAmerican-British Cooperative Group. Ann Intern Med 1985; 103: 620-625.

16. Cheson BD, Bennett JM, Kopecky KJ, Buchner T, Willman $\mathrm{CL}$, Estey $\mathrm{EH}$, et al. Revised recommendations of the International Working Group for Diagnosis, Standardization of Response Criteria, Treatment Outcomes, and Reporting Standards for Therapeutic Trials in Acute Myeloid Leukemia. J Clin Oncol 2003; 21: 4642-4649.

17. Dohner H, Estey EH, Amadori S, Appelbaum FR, Buchner T, Burnett AK, et al. Diagnosis and management of acute myeloid leukemia in adults: recommendations from an international expert panel, on behalf of the European LeukemiaNet. Blood 2010; 115: 453-474.

18. Alibhai SM, Leach M, Minden MD, Brandwein J. Outcomes and quality of care in acute myeloid leukemia over 40 years. Cancer 2009; 115: 2903-2911.

19. Prefeitura do Rio de Janeiro. População em números absolutos e percentuais, por ano, segundo grupos de idade
- 1940/2000. http://portalgeo.rio.rj.gov.br. Accessed January 30, 2011.

20. Rodrigues CA, Chauffaille ML, Pelloso LA, Ghaname FS, Kerbauy DM, Campos MG, et al. Acute myeloid leukemia in elderly patients: experience of a single center. Braz J Med Biol Res 2003; 36: 703-708.

21. Andersson TM, Lambert PC, Derolf AR, Kristinsson SY, Eloranta S, Landgren O, et al. Temporal trends in the proportion cured among adults diagnosed with acute myeloid leukaemia in Sweden 1973-2001, a population-based study. Br J Haematol 2010; 148: 918-924.

22. Lerch E, Espeli V, Zucca E, Leoncini L, Scali G, Mora O, et al. Prognosis of acute myeloid leukemia in the general population: data from southern Switzerland. Tumori 2009; 95: 303-310.

23. Astrom M, Bodin L, Nilsson I, Tidefelt U. Treatment, longterm outcome and prognostic variables in 214 unselected AML patients in Sweden. Br J Cancer 2000; 82: 13871392.

24. Estey E, Smith TL, Keating MJ, McCredie KB, Gehan EA, Freireich EJ. Prediction of survival during induction therapy in patients with newly diagnosed acute myeloblastic leukemia. Leukemia 1989; 3: 257-263.

25. Wahlin A, Hornsten $\mathrm{P}$, Jonsson $\mathrm{H}$. Remission rate and survival in acute myeloid leukemia: impact of selection and chemotherapy. Eur J Haematol 1991; 46: 240-247.

26. Weinberg OK, Seetharam M, Ren L, Seo K, Ma L, Merker JD, et al. Clinical characterization of acute myeloid leukemia with myelodysplasia-related changes as defined by the 2008 WHO classification system. Blood 2009; 113: 1906-1908.

27. Chen CC, Yang CF, Yang MH, Lee KD, Kwang WK, You JY, et al. Pretreatment prognostic factors and treatment outcome in elderly patients with de novo acute myeloid leukemia. Ann Oncol 2005; 16: 1366-1373.

28. Kantarjian H, O'Brien S, Cortes J, Giles F, Faderl S, Jabbour E, et al. Results of intensive chemotherapy in 998 patients age 65 years or older with acute myeloid leukemia or high-risk myelodysplastic syndrome: predictive prognostic models for outcome. Cancer 2006; 106: 1090-1098.

29. Wells RJ, Arthur DC, Srivastava A, Heerema NA, Le Beau $M$, Alonzo TA, et al. Prognostic variables in newly diagnosed children and adolescents with acute myeloid leukemia: Children's Cancer Group Study 213. Leukemia 2002; 16: 601-607.

30. Chen CY, Tai CH, Tsay W, Chen PY, Tien HF. Prediction of fatal intracranial hemorrhage in patients with acute myeloid leukemia. Ann Oncol 2009; 20: 1100-1104.

31. Anonymous. Acute myelogenous leukemia with an $8 ; 21$ translocation. A report on 148 cases from the Groupe Francais de Cytogenetique Hematologique. Cancer Genet Cytogenet 1990; 44: 179.

32. Thiede C, Steudel C, Mohr B, Schaich M, Schakel U, Platzbecker $\mathrm{U}$, et al. Analysis of FLT3-activating mutations in 979 patients with acute myelogenous leukemia: association with $\mathrm{FAB}$ subtypes and identification of subgroups with poor prognosis. Blood 2002; 99: 4326-4335.

33. Mrozek K, Heerema NA, Bloomfield CD. Cytogenetics in acute leukemia. Blood Rev 2004; 18: 115-136.

34. Grimwade D. The clinical significance of cytogenetic abnormalities in acute myeloid leukaemia. Best Pract Res Clin Haematol 2001; 14: 497-529. 